\title{
PAPER
}

\section{Acceptance and Use}

I.R. HOFFMAN, V. ROOS, A. STOLS, D.M. BOHMAN. Older people's user patterns of mobile phones in South Africa. Gerontechnology 2018;17(Suppl):57s; https://doi.org/10.4017/gt.2018.17.s.057.00 Purpose Globally and in South Africa a growth in population ageing will consequently result in increasing care needs for older persons ${ }^{1}$. Given the deep penetration of mobile technology in developing countries (in Sub-Saharan Africa) it is expected to potentially play a more prominent role in social and health care provision ${ }^{2}$. The aim of this study is to explore older persons' user patterns and how intra/intergenerational relations manifest through the use of mobile phones in a South African context. Method A convergent parallel mixed methods design was employed $^{3}$. Participants were representative of a broad range of different socio-economic levels based on the Living Standards Measure (LSM) scale. Quantitative data was collected by using a self-constructed questionnaire $(n=125)$, which was analysed using descriptive statistics and a chi-square test. Qualitative data were gathered by using semi-structured $(n=23)$ and group interviews $(n=10)$ as well as the Mmogo-method ${ }^{\circledR 4}$, a visual data-collection method $(n=19)$ and analysed thematically. Results \& Discussion Findings indicated that the majority of older persons mainly use two functions of their mobile phones: to make and receive calls and sms' (texting) contact mostly in relation to their children and grandchildren. The limited knowledge and skill and in some instances negative attitude of older persons hamper full utilisation of their phones. Older persons across all LSM groups resort to other people to assist them, based on their assessment of the other person's knowledge, skill and attitude - constituting mobile use by older persons as an essentially intra/intergenerational project. Suitable interventions should include appropriate educational opportunities for all older persons, despite their level of knowledge and skills, but the importance of people who are perceived as competent is highly appraised by the older persons and interventions should also focus on this possibility.

\section{References}

1. Vlachantoni A, Shaw R, Willis R, Evandrou M, Falkingham J, Luff R. Measuring unmet need for social care amongst older people. Population Trends 2011;145:56-72

2. Gillwald A, Simon JP. The ICT Landscape in BRICS Countries: South Africa. Digiworld Economic Journal, 2012;86(2):195-208

3. Creswell JW, Plano Clark VL. Designing and conducting mixed methods research (2nd ed.). Thousand Oaks, CA: Sage; 2011

4. Roos V. The Mmogo-method®: discovering symbolic community interactions. Journal of Psychology $n$ Africa, 2008;18(4):659-668

Keywords: care, intergenerational relationships, mobile phone technology, older persons

Address: Department of Health, Faculty of Engineering, Blekinge Institute of Technology, Sweden;

E:dbh@bth.se 